\title{
$-1$ \\ RELATO DE PESQUISA \\ Investigando as Potencialidades dos Ambientes Virtuais de Ensino Aprendizagem na Formação Continuada de Professores
}

\section{Temática: Educação a Distância: Estudos de Casos}

Autores:

Professor Doutor Fábio da Purificação de Bastos*

Mestranda Mara Denize Mazzardo**

\section{Resumo}

O trabalho aqui relatado tem por objetivo investigar, através da InvestigaçãoAção Escolar (IAE), as Potencialidades dos Ambientes Virtuais de Ensino Aprendizagem $\left(\mathrm{AVEA}^{1}\right.$ ) para Internet, na Formação Continuada de Professores. A pesquisa está sendo desenvolvida no PPGE - Mestrado em Educação da UFSM, Linha de Pesquisa de Formação de Professores, pela aluna Mara Denize Mazzardo, sob orientação do professor Dr. Fábio da Purificação de Bastos.

Palavras Chaves: Formação de Professores, Investigação-Ação Escolar, Ambientes Virtuais de Ensino Aprendizagem, Educação Dialógico-Problematizadora e Software Livre.

\section{Researching Virtual Environment for Teaching-Learning Potentialities in Teachers Continued Formation.}

\begin{abstract}
This paper's purpose is to investigate, thru Action Research, the Virtual Environment for Teaching-Learning's potentialities for Internet in Continued Formation for Teachers. The research is in curse in UFSM's PPGE - Master degree in Education, by student Mara Denize Mazzardo, orientated by Ph D Fábio da Purificação de Bastos.

\section{Keywords}

Teachers Formation, Action Research, Virtual Environment for Teaching-Learning, Dialog-Problematical Education, Free Software.

\section{Contexto e Detalhamento das Atividades}

A educação está sendo cada vez mais reconhecida, através de ações concretas, como alavancadora do desenvolvimento do país, possibilitando também a superação das desigualdades sociais.

O aumento do número de estudantes principalmente na Educação Básica, o maior nível de competência dos trabalhadores exigidos pelos sistemas econômicos e as

\footnotetext{
* Professor Doutor Fábio da Purificação de Bastos. Universidade Federal de Santa Maria, Centro de Educação, Departamento de Metodologia do Ensino - UFSM. fbastos@ce.ufsm.br

** Mestranda do PPGE - Mestrado em Educação - UFSM. Professora da Educação Básica da Rede Pública do RS. mmazzardo@mail.ufsm.br

${ }^{1}$ Optamos pela denominação Ambientes Virtuais de Ensino-Aprendizagem para destacar e valorizar o papel do professor no planejamento e implementação das atividades didáticas desses ambientes. 
Políticas Públicas Educacionais implementadas (Lei de Diretrizes e Bases da Educação Nacional, Parâmetros Curriculares Nacionais) são alguns exemplos que comprovam essa realidade.

Assim, os desafios para a escola são maiores, desafios que demandam professores capacitados em suas disciplinas, procedimentos didáticos adequados às novas concepções de ensino-aprendizagem e aos novos recursos (Meios TecnológicoComunicativos, principalmente os Informáticos), em busca constante de saberes que poderão melhorar sua atuação profissional e, em conseqüência, a aprendizagem dos alunos.

Frente a essas demandas a Formação Continuada dos Professores torna-se imperiosa. As questões que surgem são: Como realizá-la? De que maneira oportunizar atividades formativas de qualidade para o grande número de professores da Educação Básica?

$\mathrm{Na}$ procura de respostas para essas questões estamos investigando, através da IAE, o potencial dos AVEA para viabilizar e aumentar o acesso à Formação Continuada para os Professores da Educação Básica.

Ao implementar o projeto destacamos alguns fatores importantes para a obtenção de resultados positivos:

1) A necessidade de vivenciar situações de aprendizagem que envolvam recursos e procedimentos metodológicos inovadores no processo de Formação Continuada dos Professores e não somente ouvir sobre.

2) Ter uma proposta didático-metodológica para o AVEA - a ênfase dada neste trabalho para as metodologias, os procedimentos didáticos, é decorrente da preocupação em explorar as potencialidades desses recursos nas situações de ensino-aprendizagem e "evitar o deslumbramento que tende a levar ao uso mais ou menos indiscriminado da tecnologia por e em si, ou seja, mais por suas virtualidades técnicas do que por suas virtudes pedagógicas" (Belloni, 1999, p. 73). O conhecimento que queremos não é somente aprender a apertar botões, e sim, tomar decisões e resolver problemas (Schuck, 1997) citado por (Schlünzen Jr., 2003).

Assim, sugerimos uma modelização didático-metodológica que visa, além das habilidades no manejo dos recursos informáticos, a participação, o questionamento, o diálogo, a ação e as reflexões decorrentes das situações de formação.

Essa modelização contempla: situações de formação continuada, presencial e a distância, mediadas por tecnologias informáticas livres e um Ambiente Virtual de Ensino-Aprendizagem para Internet - $\mathrm{AMEM}^{2}$ : Ambiente Multimídia para Educação Mediada por Computador), o qual pode ser acessado no endereço http://amem.ce.ufsm.br, Educação Dialógico-Problematizadora - EDP, a Investigaçãoação Escolar - IAE e a Resolução de Problemas - RP. Essa Modelização é representada na Figura 1.

\footnotetext{
${ }^{2}$ O AMEM é um ambiente multimídia desenvolvido por uma equipe multidisciplinar (Ensino de CNMT, Pedagogia, Informática, Engenharia de Produção e design) da UFSM. Destina-se à educação presencial, semipresencial e a distância. Possui recursos para comunicação (mensagens, fóruns, salas de discussão), planejamento, implementação e acompanhamento das aulas pelo professor. O aluno conta com recursos como biblioteca, campo para enviar as Tarefas Extraclasse e os recursos de comunicação. 
Figura 1 - Representação Gráfica da Modelização proposta.

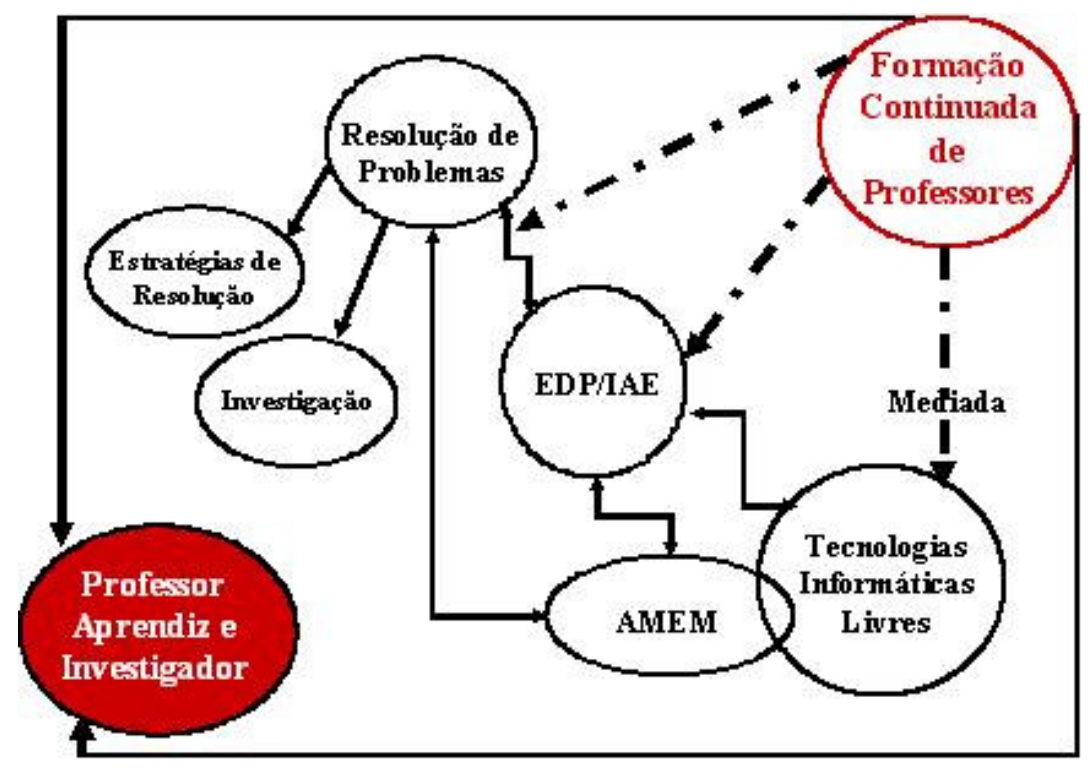

Para desenvolver a pesquisa montamos um curso - "Produção de Material Didático Através da Internet: O Saber e o Saber Ensinável” -, tendo como público alvo professores da Educação Básica da Rede Pública da cidade de Santa Maria - RS, que estão atuando em sala de aula, em unidades escolares que possuem Laboratório de Informática conectado à Internet. $\mathrm{O}$ curso acopla as modalidades Presencial e a Distância - 14 horas presencial e 26 a distância.

Após a divulgação do curso nas escolas, preenchemos um protocolo com os 25 inscritos para então definir o grupo. As aulas presenciais acontecem no laboratório de informática do Colégio Agrícola Santa Maria e as atividades a distância são mediadas pelo AMEM.

Quanto ao Software Livre, optamos pela distribuição Linux - Kalango 1.0 - que roda a partir do drive de CD. Essa distribuição contém o OpenOffice 1.1.

O conteúdo principal é a Transposição Didática dos Saberes (da disciplina de atuação do professor, em consonância com os Parâmetros Curriculares Nacionais PCN) pesquisados na Rede. Estudo e discussão sobre os PCN, educação Mediada pelas Tecnologias Informáticas Livres e a Produção de Material Didático tendo a Internet como fonte de Saber.

As aulas foram planejadas observando-se Três Momentos Pedagógicos Dialógico-Problematizadores (TMPDP) organizados por Abegg, De Bastos e Mallmann (2001) a partir da proposta de Angotti e Delizoicov (1990).

\section{Dificuldades}

O variado material didático necessário como referencial teórico, o planejamento das aulas, a pesquisa dos Sites de referência para cada área e ou disciplina exigiram muitas horas de trabalho. Também o preenchimento do protocolo foi demorado porque optamos por encontrar os professores nas escolas. Conciliar os horários e até encontrar um local para conversar foram algumas das dificuldades enfrentadas antes do início das aulas.

Outra dificuldade que enfrentamos é a necessidade de computador com uma boa 
configuração de hardware (mínimo de $128 \mathrm{MB}$ de memória) para rodar o Kalango.

O curso está sendo desenvolvido com um grupo de 9 professores. As dificuldades decorrentes da vivência prática estão surgindo:

- Trabalho com um recurso (Internet) que não faz parte do cotidiano - os professores que não possuem computador e acesso à Internet em casa, têm de conciliar horários para desenvolver as atividades na escola.

- A falta de familiaridade com os recursos da Internet torna as atividades mais complexas, dificultando a exploração das ferramentas do ambiente (participação nos fóruns, envio de mensagens, pesquisa na Biblioteca, execução da Tarefa Extraclasse).

- Organização do tempo para estudo - a Educação a Distância, que atrai pela suposta facilidade, exige dedicação dos estudantes e tempo disponível para estudo, realização das atividades e interação com professor e colegas.

\section{Avanços}

- Mesmo com as dificuldades com o ambiente as alunas estão acompanhando as atividades.

- O interesse manifestado por atividades que incluem os recursos informáticos na formação continuada e no processo ensino-aprendizagem.

- A dedicação ao curso e aos temas estudados - as atividades do curso são realizadas fora do horário de trabalho.

- As atividades e os temas estudados a distância estimulam a discussão nas aulas presenciais.

\section{Algumas Considerações}

Este trabalho está em andamento, porém já podemos traçar algumas considerações:

- Os professores necessitam de maior contato e conhecimento dos recursos informáticos tanto na formação continuada como nas atividades didáticas.

- Acompanhamento constante pelo professor das atividades do curso, estimulando a participação e realização das tarefas, provocando debates e questionamentos.

- A investigação pelos próprios professores alunos (através da IAE) das potencialidades desses recursos na sua formação e no trabalho na escola.

- Disponibilidade de tempo para estudo e execução das atividades.

- Os AVEAS possibilitam a adequação dos horários de estudo às necessidades dos alunos.

- Os recursos do AMEM, como biblioteca com os materiais didáticos disponibilizados e o envio das Tarefas Extraclasse através do próprio ambiente, agilizam a execução das atividades.

- Faz-se necessário um debate maior com os professores sobre o Software Livre no contexto educacional brasileiro.

A pesquisa continua, com a turma começando a produção do material didático, que será implementado na escola na última etapa do trabalho. 
Referências bibliográficas

ABEGG, I., DE BASTOS, F. DA P. e MALlMANN, E. M. Momentos Pedagógicos Dialógico-Problematizadores: sendo desafiados nas aulas. UFSM/PPGE, Santa Maria, 2001.

ALMEIDA, M. E. B. Tecnologia e Educação a Distância: Abordagens e Contribuições dos Ambientes Digitais e Interativos de Aprendizagem. ANPEd, 2003.

ANGotTi, J. A. P. e DELIZOICOV, D. Metodologia do Ensino de Cências. Cortez, São Paulo, 1990.

BELLONI, M.L. Educação a Distância. Campinas, SP, Autores Associados, 1999.

CARR, W. e KEMMIS, S. Teoria Crítica de la Enseñanza: Investigación-acción en la Formación del Profesorado. Barcelona: Martinez Roca, 1988.

DE BASTOS, F. P. Por que não temos investigação-ação nas escolas? In: Revista Eletrônica de Educação Paidéias@ Idéias - Edição No 03 de 11 de janeiro de 2002.

ELLIOTT, J. What is Action-Research in Schools? Journal of Curriculum Studies, vol.10, no 4: 335-7,1978.

FERNANDEZ, E. G. Ambiente Multimidia para Educação Mediada por Computador na Perspectiva da IAE: Modelagem e Implemento. Dissertação de Mestrado, PPGEP/CT/UFSM, 2003.

FREIRE, P. Pedagogia da Autonomia: saberes necessários à prática educativa. São Paulo, Paz e Terra, 1996.

Pedagogia do Oprimido. Rio de Janeiro, Paz e Terra, 1987.

GIL PÉREZ, D., MARTINEZ-TORREGROSA, J., RAMIREZ, L., DUMAS-CARRÉ, A., GOFARD, M. e PESSOA de CARVALHO, A.M. (1992). Questionando a didática de R.P.: elaboração de um modelo alternativo. Caderno Catarinense de Ensino de Física, 9(1):7-19.

LOPES, J. Bernardino. Perspectivar Novas Modelizações da Prática Relevantes para o Conhecimento Profissional do Futuro Professor de Física. Disponível em:<http://www.educ.fc.ul.pt/recentes/mpfip/pdfs/bernardinolopes.pdf>

SOUZA, Carlos Alberto. Investigação-ação Escolar e Resolução de Problemas de Física: O Potencial dos Meios Técnológico-Comunicativo. Tese de doutoramento, PPGE - UFSC, Florianópolis, 2004.

SCHLÜNZEN JUNIOR, Klaus. Aprendizagem, Cultura e Tecnologia. São Paulo: Editora UNESP, 2003. 